\title{
Impact of COVID-19 Lockdown on Dry Eye Disease Symptoms
}

\author{
Mona A. Nassief ${ }^{1}$, Sherein M. Hagras ${ }^{2}$, Reham A. Amer ${ }^{3}$, Ameera G. Abdelhameed ${ }^{2}$ \\ 1= Lecturer of ophthalmology, Tanta University, Faculty of Medicine, Egypt \\ $2=$ Associate professor of ophthalmology, Mansoura University, Faculty of Medicine, Egypt \\ $3=$ Lecture of psychiatry in neuropsychiatry department, Tanta University, Faculty of Medicine, Egypt
}

*Corresponding author: Sherein Hagras, Ophthalmic center, Faculty of Medicine, Mansoura University.
Al-Gomohoria Street, Mansoura (Postal code: 35516), Egypt. Email address: shereinhagras@gmail.com
Received: 8-2-2021, Accepted: 24-5-2021, Published online:10-6-2021
EJO(MOC) 2021;1:70-84.
Running title: COVID-19 Lockdown and DED

ABSTRACT

Aim: to evaluate the potential relation between the lockdown during COVID-19 pandemic and the symptoms of dry eye disease (DED).

Methods: a questionnaire based- study conducted via an electronic survey during the period of COVID19 lockdown. The survey included participants' demographic data, potential lockdown associated risk factors of DED. Ocular Surface Disease Index questionnaire (OSDI) was applied for diagnosis of DED. A modified questionnaire was utilized for assessing the DED severity. Perceived Stress Scale 4 (PSS-4) and the 4-item Patient Health Questionnaire for Anxiety and Depression (PHQ-4) were used to assess the psychological status as a potential risk factor for DED. Univariate and multivariate logistic regression analysis were used to assess risk factor for developing DED. Multivariate regression analysis was used to study risk factors affecting the severity.

Results: The survey included 455 participants. Self-assessed DED was diagnosed in 135 (29.7\%) participants based on OSDI scores. Symptoms were mild in $48.1 \%$, moderate in $18.0 \%$ \& severe in $11.6 \%$. Multivariate logistic regression analysis revealed that increased duration of Visual display terminals (VDT) use during day, presence of anxiety, and increased PSS-4 by one point were significantly associated with increased likelihood of DED by 1.097 , 2.167, and 1.792, respectively. Multivariate multiple regression analysis demonstrated that increased severity of DED was associated with longer duration of VDT use during day and increased PSS-4 by one point ( $<<0.001$ ).

Conclusion: The COVID-19 lockdown may have led to increased psychological stress and prolonged use of VDTs, which were significantly associated with increased risk and severity of DED.

Keywords: COVID-19; Dry eye syndromes; Lockdown; Stress; Visual display terminal

\section{INTRODUCTION}

Corona virus disease 2019 (COVID-19) pandemic caused by a "severe acute respiratory syndrome corona virus (SARS-CoV-2)", represents a major health problem owing to its rapid transmission from infected to healthy individuals. Unprecedented public health measures of home quarantine has been imposed in order to limit the extent of the outbreak ${ }^{1-3}$. Though these measures are crucial for controlling this pandemic, there has been some concern regarding their potential impact on the ocular surface integrity, especially, developing and or worsening of dry eye disease (DED) symptoms ${ }^{4}$.

Egyptian Journal of Ophthalmology, a publication of Mansoura Ophthalmic Center.

Address: Mansoura Ophthalmic Center, Mansoura University, Mansoura, Egypt.

Website: https://ejomos.journals.ekb.eg

Tel. 0020502202064. Fax. 0020502202060.

E-mail: ejo@mans.edu.eg 
According to the International Dry Eye Work Shop, dry eye is defined as a multifactorial disease of the tears and ocular surface that results in symptoms of discomfort, visual disturbance, and tear film instability with potential damage to the ocular surface. It is accompanied by increased osmolarity of the tear film and inflammation of the ocular surface ${ }^{5}$. Patients with DED commonly present with eye discomfort, gritty sensation, eye redness, blurred vision, light sensitivity, ocular fatigue, and chronic pain ${ }^{6}$. These symptoms can impact negatively the patients' quality of life by restricting some daily activities, such as reading or driving ${ }^{7-8}$.

Several risk factors have been implicated in triggering the inflammatory reaction in DED, including autoimmune diseases, central sensitization syndromes, long-term use of some drugs, chemical irritants, longterm wearing of contact lenses, alteration of corneal innervation (viral infections, trauma, chemicals, refractive surgery), exposure to high levels of pollutants $^{9}$, low humidity ${ }^{10}$, and visual display terminals

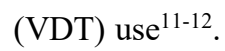

Psychiatric disorders, particularly anxiety and depression have been reported to be associated with $\mathrm{DED}^{13}$. The current stress caused by COVID-19 pandemic and the perceived increase of VDT use during the lockdown imposed in most countries inspired the conduction of the present study to evaluate the potential relation of lockdown during COVID-19 on prevalence and severity of ocular surface symptoms.

\section{PATIENTS AND METHODS}

A questionnaire based-study was conducted via an electronic survey. The study follows the tenets of declaration of Helsinki. An approval from Institutional Review Board of Tanta University, Egypt was obtained (approval code: 33897/6/20). Participants from Middle East region were invited via social media sites to complete a self-administered electronic questionnaire.
The questionnaire was uploaded for 2 weeks in June 2020. Before this period, there was complete curfew in most of the countries included for nearly 3 months. Participants voluntarily answered the questions and submit their answers which were considered as a consent for participation. The electronic questionnaire was preceded by a statement that informed the participants about the study and its aim. Names of the participants remained confidential.

The questionnaire involved questions regarding participants' socio-demographic data (age, sex, occupation, smoking habits), possible medical risk factors (medical history, error of refractions, use of eyeglasses, contact lenses, and history of refractive surgery) and possible life style changes during the period of lockdown (change in work burden during lockdown and increased VDT use). Perceived Stress Scale 4 (PSS4) and the 4-item Patient Health Questionnaire for Anxiety and Depression (PHQ-4) were used to assess the possible effects of the lockdown on the psychological status as a potential risk factor for DED. Ocular Surface Disease Index (OSDI) was used to diagnose DED, modified questionnaire of dry eye symptoms was used to assess the severity of DED.

\section{Ocular Surface Disease Index (OSDI)}

The OSDI consists of 12-items, which is used to diagnose as self-assessed $\mathrm{DED}^{14}$. Each of the 12 items was given a score of $0-4$. The total OSDI score is calculated with the following formula: OSDI score $=$ [sum of the scores for all questions answered x 100]/total number of questions answered] $x 4$. The minimum OSDI score is 0 and the maximum is 100 . Participants were divided into DED (scores $\geq 13$ ) and non - DED (scores $<13)$. 
Modified questionnaire for the severity of DED symptoms

This was generated by modifying dry eye symptom questions suggested in the literature ${ }^{15,16}$ and consisted of 8questions pertaining to most common DE symptoms; eye fatigue, grittiness, eye burning, red eye, watering, blurred vision, sticky sensations and sensitivity of light. Each participant was asked to describe the severity of each symptom which was subsequently given a score as following: absent $(=0)$, uncomfortable $(=1)$, irritating but not interfering with life $(=2)$, irritating and interfering with life $(=3)$. Sum of the scores was used to classify the severity of the symptoms into mild (scores 1-8). Moderate (9-16) and severe (>16).

The 4-item Patient Health Questionnaire for Anxiety and Depression (PHQ-4)

The PHQ-4 questionnaire was graded from 0 to 3 . Two subscales exist for anxiety and depression. A total score $\geq 3$ for the first two questions suggest anxiety, while a total score $\geq 3$ for the second two questions suggests depression ${ }^{17}$.

\section{The Perceived Stress Scale 4 (PSS-4)}

The PSS-4 questionnaire included 4 questions, which assess the perceived psychological stress. The total score ranges from 0 to 16 ; the higher the score, the more perceived psychological stress ${ }^{18}$.

\section{Statistical analysis}

The responses to the questionnaire were downloaded from Google forms as an Excel datasheet and then were opened in Statistical Package for Social Sciences(SPSS), version 26. Categorical data was summarized as frequencies and percentages. The association between two categorical variables were evaluated using either Pearson's Chi square test for independence, Fisher's exact test or Fisher-Freeman-Halton exact test as appropriate. Numerical data were assessed using the
Shapiro-Wilk test for normality. Normally distributed variables were summarized as mean \pm standard deviation (SD) and comparisons between the two groups were carried out using Independent samples T-test. Marginal homogeneity test was performed to compare durations of VDT use before and during COVID-19 pandemic. Multivariate binomial logistic regression analysis was conducted including all relevant risk factors which had a $\mathrm{p}$ value in the univariate analysis $<0.2$, according to Bursac et al. ${ }^{19}$. The $\mathrm{p}$ value, odds ratio (OR), and $95 \%$ confidence intervals (CI) for each risk factor were reported. Multiple regression analysis was performed to assess risk factors that may affect severity of DED. The $\mathrm{p}$ values, regression coefficients, and their $95 \%$ CI were reported for each risk factor. A $\mathrm{p}$ value $\leq 0.05$ was adopted for interpretation of the results of statistical tests.

\section{RESULTS}

A total of 469 participants responded to the questionnaire, out of whom 455 completed all questions and were included in the study. According to the OSDI, responders were classified into DED and non-DED. One hundred thirty-five (29.7\%) responders were identified as having dry eye. Table (1) compares the sociodemographic factors between DED and non-DED groups. The DED group had a significantly higher percentage of females $(p=0.025)$. Significantly higher percentage of responders in the DED group worked from home $(\mathrm{p}=0.018)$. There was no significant difference regarding the age $(\mathrm{p}=0.057)$, occupation $(\mathrm{p}=0.770)$, working with digital screens $(p=0.242)$, or smoking ( $p$ $=0.612$ ) between the two groups. The DED group had a significantly higher percentage of using antiinflammatory drugs $(\mathrm{p}=0.003)$, antihistamines $(\mathrm{p}=$ $0.001)$, previous history of dry eye $(\mathrm{p}<0.001)$, and astigmatism $(\mathrm{p}=0.031)$. Eyeglasses wearer were significantly lower in DED group $(\mathrm{p}=0.023)$. 
Table (1): Comparison of socio-demographic and medical risk factors between participants with dry eye disease (DED) and those without (total $n=455)$

\begin{tabular}{|c|c|c|c|c|c|c|c|}
\hline \multirow{2}{*}{\multicolumn{2}{|c|}{\begin{tabular}{|l} 
\\
Age (years) Mean \pm SD
\end{tabular}}} & \multirow{2}{*}{\multicolumn{2}{|c|}{$\begin{array}{c}\text { DED } \\
(\mathbf{n}=\mathbf{1 3 5}) \\
29.9 \pm 10.3 \\
\end{array}$}} & \multicolumn{2}{|c|}{$\begin{array}{c}\text { Non-DED } \\
(\mathrm{n}=\mathbf{3 2 0})\end{array}$} & \multirow{3}{*}{$\begin{array}{c}\text { Test statistic } \\
1.907^{\mathrm{a}} \\
5.036^{\mathrm{b}}\end{array}$} & \multirow{3}{*}{$\begin{array}{c}\mathbf{P} \\
0.057 \\
\mathbf{0 . 0 2 5}\end{array}$} \\
\hline & & & & & \pm 11.6 & & \\
\hline \multirow[t]{2}{*}{ Gender } & Female & 103 & $76.3 \%$ & 210 & $65.6 \%$ & & \\
\hline & Male & 32 & $23.7 \%$ & 110 & $34.4 \%$ & & \\
\hline \multirow[t]{7}{*}{ Occupation } & Student & 46 & $34.1 \%$ & 96 & $30.0 \%$ & \multirow[t]{7}{*}{$3.387^{\mathrm{c}}$} & \multirow[t]{7}{*}{0.770} \\
\hline & Housewife & 8 & $5.9 \%$ & 22 & $6.9 \%$ & & \\
\hline & Unemployed & 6 & $4.4 \%$ & 20 & $6.3 \%$ & & \\
\hline & Retired & 1 & $0.7 \%$ & 3 & $0.9 \%$ & & \\
\hline & Self-employed & 0 & $0.0 \%$ & 6 & $1.9 \%$ & & \\
\hline & Employee & 10 & $7.4 \%$ & 24 & $7.5 \%$ & & \\
\hline & Professional & 64 & $47.4 \%$ & 149 & $46.6 \%$ & & \\
\hline \multirow{2}{*}{$\begin{array}{l}\text { Occupation with } \\
\text { digital screen use }\end{array}$} & No & 70 & $51.9 \%$ & 185 & $57.8 \%$ & \multirow[t]{2}{*}{$1.369^{b}$} & \multirow[t]{2}{*}{0.242} \\
\hline & Yes & 65 & $48.1 \%$ & 135 & $42.2 \%$ & & \\
\hline \multirow{4}{*}{$\begin{array}{l}\text { Work during last } \\
\text { month }\end{array}$} & No change & 22 & $16.3 \%$ & 38 & $11.9 \%$ & \multirow[t]{4}{*}{$10.057^{b}$} & \multirow[t]{4}{*}{$0.018 *$} \\
\hline & No work & 28 & $20.7 \%$ & 90 & $28.1 \%$ & & \\
\hline & Reduced duty & 29 & $21.5 \%$ & 97 & $30.3 \%$ & & \\
\hline & Work from home & 56 & $41.5 \%$ & 95 & $29.7 \%$ & & \\
\hline \multirow[t]{2}{*}{ Smoking status } & No & 118 & $87.4 \%$ & 285 & $89.1 \%$ & \multirow[t]{2}{*}{$0.257^{b}$} & \multirow[t]{2}{*}{0.612} \\
\hline & Yes & 17 & $12.6 \%$ & 35 & $10.9 \%$ & & \\
\hline \multirow{9}{*}{$\begin{array}{l}\text { Medication } \\
\text { History }\end{array}$} & Vitamins & 47 & $34.8 \%$ & 110 & $34.4 \%$ & $0.008^{\mathrm{b}}$ & 0.928 \\
\hline & Anti-inflammatory & 38 & $28.1 \%$ & 51 & $15.9 \%$ & $8.997^{\mathrm{b}}$ & 0.003* \\
\hline & Antihistamines & 45 & $33.3 \%$ & 59 & $18.4 \%$ & $11.948^{b}$ & 0.001* \\
\hline & Antihypertensive & 9 & $6.7 \%$ & 26 & $8.1 \%$ & $0.284^{b}$ & 0.594 \\
\hline & Cardiac treatment & 1 & $0.7 \%$ & 7 & $2.2 \%$ & $\mathrm{FE}$ & 0.446 \\
\hline & Antidepressants & 8 & $5.9 \%$ & 8 & $2.5 \%$ & $\mathrm{FE}$ & 0.092 \\
\hline & \begin{tabular}{|l|} 
Antianxiety drugs \\
\end{tabular} & 7 & $5.2 \%$ & 12 & $3.8 \%$ & $0.489^{b}$ & 0.484 \\
\hline & COVID-19 treatment & 2 & $1.5 \%$ & 2 & $0.6 \%$ & $\mathrm{FE}$ & 0.586 \\
\hline & Anti-glaucomatous drops & 12 & $8.9 \%$ & 25 & $7.8 \%$ & $0.147^{\mathrm{b}}$ & 0.701 \\
\hline \multirow{7}{*}{ Medical history } & Hypertension & 27 & $20.0 \%$ & 76 & $23.8 \%$ & $0.762^{\mathrm{b}}$ & 0.383 \\
\hline & Diabetes mellitus & 12 & $8.9 \%$ & 45 & $14.1 \%$ & $2.319^{b}$ & 0.128 \\
\hline & Depression & 27 & $20.0 \%$ & 57 & $17.8 \%$ & $0.302^{\mathrm{b}}$ & 0.583 \\
\hline & Anxiety & 32 & $23.7 \%$ & 62 & $19.4 \%$ & $1.085^{\mathrm{b}}$ & 0.298 \\
\hline & Autoimmune disorder & 20 & $14.8 \%$ & 42 & $13.1 \%$ & $0.230^{\mathrm{b}}$ & 0.631 \\
\hline & Vitamin D deficiency & 44 & $32.6 \%$ & 100 & $31.3 \%$ & $0.079^{\mathrm{b}}$ & 0.778 \\
\hline & Dry eye & 58 & $43.0 \%$ & 84 & $26.3 \%$ & $12.353^{b}$ & $<0.001 *$ \\
\hline \multirow{4}{*}{$\begin{array}{l}\text { Did you have weak } \\
\text { vision }\end{array}$} & Error of refraction & 71 & $52.6 \%$ & 139 & $43.4 \%$ & $3.202^{b}$ & 0.074 \\
\hline & Near sight & 38 & $28.1 \%$ & 86 & $26.9 \%$ & $0.078^{\mathrm{b}}$ & 0.781 \\
\hline & Far sight & 15 & $11.1 \%$ & 23 & $7.2 \%$ & $1.910^{\mathrm{b}}$ & 0.167 \\
\hline & Astigmatism & 16 & $11.9 \%$ & 19 & $5.9 \%$ & $4.677^{b}$ & 0.031* \\
\hline \multirow{3}{*}{$\begin{array}{l}\text { Correction } \\
\text { of vision }\end{array}$} & Glass wearer & 44 & $32.6 \%$ & 141 & $44.1 \%$ & $5.177^{\mathrm{b}}$ & 0.023* \\
\hline & Previous refractive surgery & 3 & $2.2 \%$ & 11 & $3.4 \%$ & $0.470^{\mathrm{b}}$ & 0.493 \\
\hline & Contact lens user & 6 & $4.4 \%$ & 20 & $6.3 \%$ & $0.574^{\mathrm{b}}$ & 0.448 \\
\hline
\end{tabular}

n: number; SD: standard deviation; a: Independent samples T-test; b: Pearson's Chi square test for independence; c: Fisher-Freeman-Halton exact test; FE: Fisher's exact test ; * significant at $\mathrm{p} \leq 0.05$. 
Table (2) summarizes dry eye-related symptoms during the last month (the COVID-19 lockdown) among the participants. Figure 1 illustrates the severity of the DED among the participants according to the modified questionnaire scale.

Table (2): Dry eye-related symptoms during last month and their severity among the studied participants $($ total $n=455)$

\begin{tabular}{|l|c|c|c|}
\hline Dry eye-related & Uncomfortable & irritating but not interfering & irritating and interfering \\
with life & n life \\
Eyme fatigue & $\mathrm{n}(\%)$ & $\mathrm{n}(\%)$ \\
\hline Grittiness & $130(28.6 \%)$ & $33(16.3 \%)$ & $14(3.1 \%)$ \\
\hline Eye burning & $147(72.8 \%)$ & $41(16.1 \%)$ & $22(10.9 \%)$ \\
\hline Red eye & $200(78.7 \%)$ & $29(14.2 \%)$ & $13(5.1 \%)$ \\
\hline Watering & $166(81.4 \%)$ & $27(12.3 \%)$ & $9(4.4 \%)$ \\
\hline Blurred vision & $178(81.3 \%)$ & $34(15.7 \%)$ & $14(6.4 \%)$ \\
\hline Sticky sensation & $170(78.7 \%)$ & $8(5.3 \%)$ & $12(5.6 \%)$ \\
\hline Sensitivity of light & $135(89.4 \%)$ & $20(11.4 \%)$ & $8(5.3 \%)$ \\
\hline
\end{tabular}

$\mathrm{n}=$ number

\section{Severity of dry eye-related symptoms}

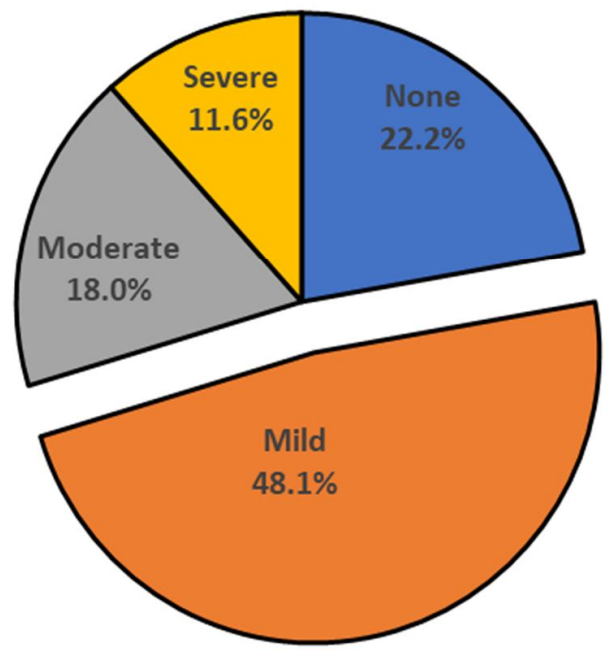

Figure (1): Severity of dry eye-related symptoms (total $n=455$ ). 
Comparing the two groups as regard the pattern of VDT use during the COVID-19 lockdown revealed a significantly longer duration of VDT use by the DED group during night before COVID-19 $(\mathrm{p}=0.045)$ and during day and night during COVID-19 lockdown (p $<0.001$ and 0.002 , respectively). There was no significant difference between the two groups regarding the number of digital screens used $(p=0.327)$, type of digital devices used (whether smart phone, laptop, or tablet; $\mathrm{p}=0.382,0.732$, and 0.310 ), or VDT use during day before COVID-19 lockdown $(\mathrm{p}=0.154)$.

Figures (2) and (3) demonstrate the change in duration of VDT use within each group before COVID19 pandemic and during COVID-19 lockdown. Duration of VDT use during COVID-19 lockdown was increased significantly, both during day and night in each group $(\mathrm{p}<0.001)$.

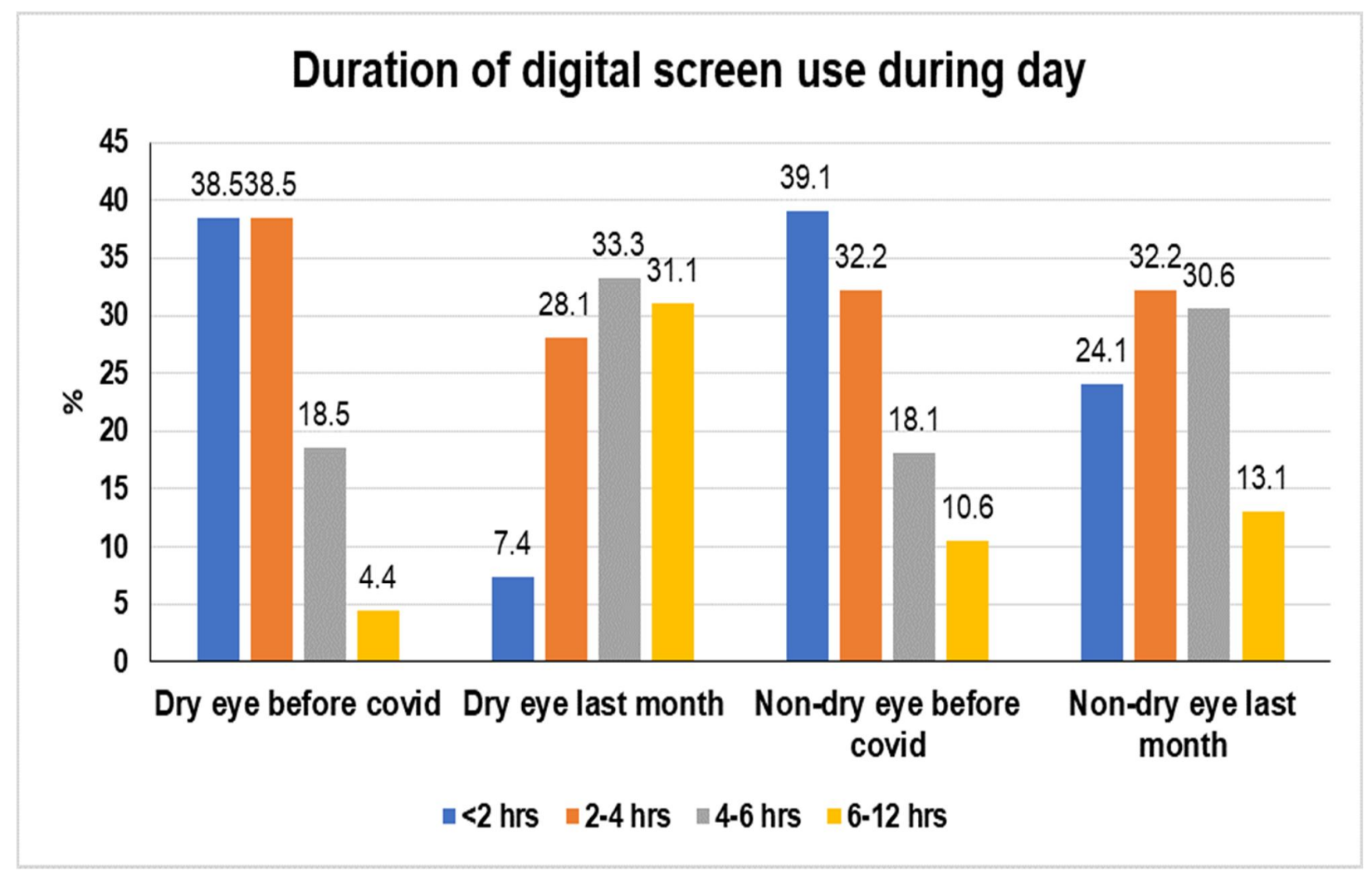

Figure (2): Comparison of duration of VDT use during day before COVID-19 and during last month within each group (Marginal homogeneity test: dry eye: test statistic $=8.723, \mathrm{p}<0.001$; non-dry eye: test statistic $=5.559, \mathrm{p}<0.001$ ) 


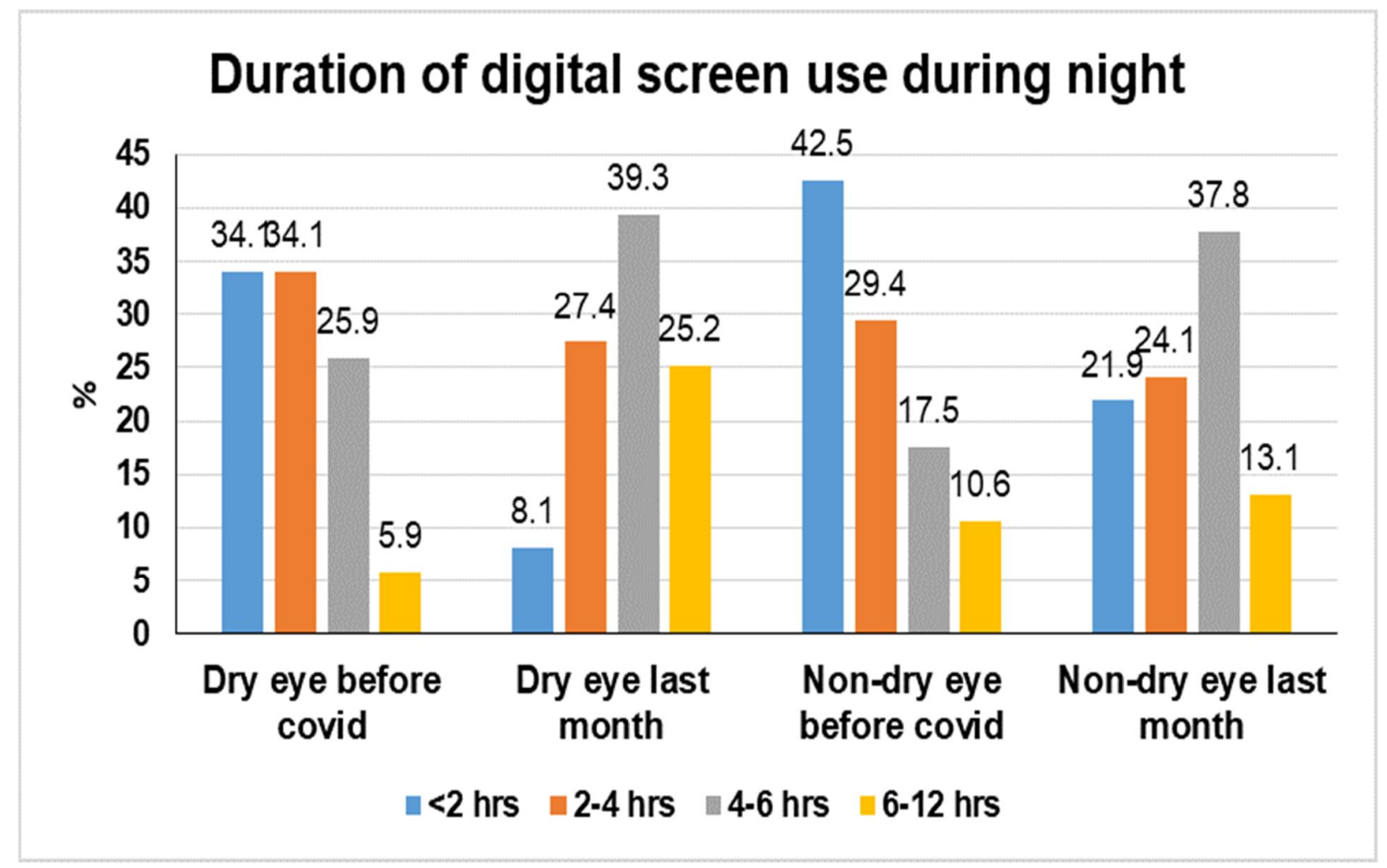

Figure (3): Comparison of duration of VDT use during night before COVID-19 and during last month within each group (Marginal homogeneity test: dry eye: test statistic $=7.443, \mathrm{p}<0.001$; non-dry eye: test statistic $=8.063, \mathrm{p}<0.001$ ).

Table (3) demonstrates symptoms of anxiety, depression and stress among the responders. The mean \pm SD of PHQ-4 score was significantly higher in the DED than in the non-DED group $(6.2 \pm 2.9$ vs $4.4 \pm 2.9$, respectively; $\mathrm{p}<0.001$ ). The percentages of responders with anxiety and depression were significantly higher in the DED group (57\% vs $29.1 \%, \mathrm{p}<0.001$ and $77.8 \%$ vs
$43.8 \%, \mathrm{p}<0.001$, respectively). The items of stress scale4 showed significant differences between the two groups $(<0.001)$ with higher level of stress in the DED group. The mean \pm SD of the sum of stress scale- 4 was significantly higher in the DED group $(10.5 \pm 2.3$ vs 7.2 \pm 2.5 , respectively; $\mathrm{p}<0.001)$. 
Table (3): Comparison of perceived stress, anxiety, and depression between dry eye disease (DED) and nonDED groups (total $n=455)$

\begin{tabular}{|c|c|c|c|c|c|c|c|}
\hline \multirow{5}{*}{$\begin{array}{l}\text { Last month feeling nervous } \\
\text { anxious or on the edge }\end{array}$} & \multirow[b]{2}{*}{ Not at all } & \multicolumn{2}{|c|}{$\begin{array}{c}\text { DED } \\
(n=135)\end{array}$} & \multicolumn{2}{|c|}{$\begin{array}{l}\text { Non-DED } \\
(\mathrm{n}=\mathbf{3 2 0})\end{array}$} & \multirow{5}{*}{\begin{tabular}{|c|}
$\begin{array}{c}\text { Test } \\
\text { statistic }\end{array}$ \\
$31.891^{\mathrm{a}}$ \\
\end{tabular}} & \multirow{5}{*}{$\frac{\mathbf{P}}{<0.001 *}$} \\
\hline & & 12 & $8.9 \%$ & 70 & $21.9 \%$ & & \\
\hline & Several days & 54 & $40.0 \%$ & 165 & $51.6 \%$ & & \\
\hline & More than half the days & 45 & $33.3 \%$ & 66 & $20.6 \%$ & & \\
\hline & Nearly every day & 24 & $17.8 \%$ & 19 & $5.9 \%$ & & \\
\hline \multirow{4}{*}{$\begin{array}{l}\text { Last month Not being a able to } \\
\text { stop or control worrying }\end{array}$} & Not at all & 23 & $17.0 \%$ & 107 & $33.4 \%$ & \multirow[t]{4}{*}{$24.652^{\mathrm{a}}$} & \multirow[t]{4}{*}{$<0.001^{*}$} \\
\hline & Several days & 58 & $43.0 \%$ & 150 & $46.9 \%$ & & \\
\hline & More than half the days & 36 & $26.7 \%$ & 44 & $13.8 \%$ & & \\
\hline & Nearly every day & 18 & $13.3 \%$ & 19 & $5.9 \%$ & & \\
\hline \multirow{4}{*}{$\begin{array}{l}\text { Last month feeling down } \\
\text { depressed or hopeless }\end{array}$} & Not at all & 19 & $14.1 \%$ & 99 & $30.9 \%$ & \multirow[t]{4}{*}{$31.378^{\mathrm{a}}$} & \multirow[t]{4}{*}{$<0.001 *$} \\
\hline & Several days & 36 & $26.7 \%$ & 100 & $31.3 \%$ & & \\
\hline & More than half the days & 47 & $34.8 \%$ & 95 & $29.7 \%$ & & \\
\hline & Nearly every day & 33 & $24.4 \%$ & 26 & $8.1 \%$ & & \\
\hline \multirow{4}{*}{$\begin{array}{l}\text { Last month little interest in } \\
\text { doing things }\end{array}$} & Not at all & 21 & $15.6 \%$ & 85 & $26.6 \%$ & \multirow[t]{4}{*}{$23.667^{\mathrm{a}}$} & \multirow[t]{4}{*}{$0.005^{*}$} \\
\hline & Several days & 25 & $18.5 \%$ & 100 & $31.3 \%$ & & \\
\hline & More than half the days & 64 & $47.4 \%$ & 108 & $33.8 \%$ & & \\
\hline & Nearly every day & 25 & $18.5 \%$ & 27 & $8.4 \%$ & & \\
\hline \multirow[t]{2}{*}{ Psychological disorders } & Anxiety & 77 & $57.0 \%$ & 93 & $29.1 \%$ & $31.749^{\mathrm{a}}$ & $<0.001^{*}$ \\
\hline & Depression & 105 & $77.8 \%$ & 140 & $43.8 \%$ & $44.236^{\mathrm{a}}$ & $<0.001^{*}$ \\
\hline \multicolumn{2}{|l|}{ PHQ-4 sum score (Mean \pm SD) } & \multicolumn{2}{|c|}{$6.3 \pm 2.9$} & \multicolumn{2}{|c|}{$4.4 \pm 2.9$} & $6.511^{\mathrm{b}}$ & $<0.001^{*}$ \\
\hline \multirow{5}{*}{$\begin{array}{l}\text { Last month unable to control } \\
\text { the important things in your } \\
\text { life }\end{array}$} & Never & 20 & $14.8 \%$ & 116 & $36.3 \%$ & \multirow[t]{5}{*}{$32.595^{\mathrm{a}}$} & \multirow[t]{5}{*}{$<0.001^{*}$} \\
\hline & Almost never & 13 & $9.6 \%$ & 39 & $12.2 \%$ & & \\
\hline & Sometimes & 31 & $23.0 \%$ & 68 & $21.3 \%$ & & \\
\hline & Fairly often & 45 & $33.3 \%$ & 75 & $23.4 \%$ & & \\
\hline & Very often & 26 & $19.3 \%$ & 22 & $6.9 \%$ & & \\
\hline \multirow{5}{*}{$\begin{array}{l}\text { Last month Felt confident } \\
\text { about handle personal } \\
\text { problems }\end{array}$} & Very often & 5 & $3.7 \%$ & 41 & $12.8 \%$ & \multirow[t]{5}{*}{$34.077^{\mathrm{a}}$} & \multirow[t]{5}{*}{$<0.001^{*}$} \\
\hline & Fairly often & 11 & $8.1 \%$ & 56 & $17.5 \%$ & & \\
\hline & Sometimes & 39 & $28.9 \%$ & 122 & $38.1 \%$ & & \\
\hline & Almost never & 16 & $11.9 \%$ & 19 & $5.9 \%$ & & \\
\hline & Never & 64 & $47.4 \%$ & 82 & $25.6 \%$ & & \\
\hline Last month Felt that things & Very often & 12 & $8.9 \%$ & 45 & $14.1 \%$ & $20.519^{a}$ & $<0.001^{*}$ \\
\hline were going your way & Fairly often & 6 & $4.4 \%$ & 45 & $14.1 \%$ & & \\
\hline & Sometimes & 51 & $37.8 \%$ & 135 & $42.2 \%$ & & \\
\hline & Almost never & 17 & $12.6 \%$ & 28 & $8.8 \%$ & & \\
\hline & Never & 49 & $36.3 \%$ & 67 & $20.9 \%$ & & \\
\hline Last month Felt difficulties & Never & 6 & $4.4 \%$ & 121 & $37.8 \%$ & $67.786^{\mathrm{a}}$ & $<0.001 *$ \\
\hline were piling up could not & Almost never & 14 & $10.4 \%$ & 37 & $11.6 \%$ & & \\
\hline overcome & Sometimes & 33 & $24.4 \%$ & 65 & $20.3 \%$ & & \\
\hline & Fairly often & 51 & $37.8 \%$ & 76 & $23.8 \%$ & & \\
\hline & Very often & 31 & $23.0 \%$ & 21 & $6.6 \%$ & & \\
\hline Stress scale -4 sum (Mean \pm SD & & 10. & $5 \pm 2.3$ & & \pm 2.5 & $13.035^{b}$ & $<0.001^{*}$ \\
\hline
\end{tabular}

n: number; SD: standard deviation; $P H Q-4=$ Patient Health Questionnaire for Anxiety and Depression; a:

Pearson's Chi square test for independence; b: Independent samples T-test; *significant at $\mathrm{p} \leq 0.05$. 
Univariate analysis showed that DED was significantly associated with female gender $(p=0.025)$, increased work load during the last month $(\mathrm{p}=0.018)$, administration of anti-inflammatory drugs $(p=0.003)$ and antihistamines $(\mathrm{p}=0.001)$, previous history of dry eye $(\mathrm{p}<0.001)$, astigmatism $(\mathrm{p}=0.031)$, increased duration of digital screen use in the last month during day $(\mathrm{p}<0.001)$ and night $(\mathrm{p}=0.015)$, anxiety $(\mathrm{p}<0.001)$, depression $(p<0.001)$, and higher stress score $(p<0.001)$.
After adjustment for confounding factors, multivariate logistic regression analysis revealed that increased duration of Visual display terminals (VDT) use during day, presence of anxiety, and increased PSS-4 by one point were significantly associated with increased likelihood of DED by 1.097, 2.167, and 1.792, respectively ( $\mathrm{p}$ values $<0.001,0.019$, and $<0.001$, respectively) (table 4).

Table (4): Multivariate logistic regression to assess effect of potential risk factors on development of dry eye disease (total $n=455)$

\begin{tabular}{|c|c|c|c|c|}
\hline \multirow[b]{2}{*}{ Risk factors } & \multirow[b]{2}{*}{$\mathbf{P}$} & \multirow[b]{2}{*}{ OR } & \multicolumn{2}{|c|}{ 95\% CI for OR } \\
\hline & & & Lower & Upper \\
\hline Age (years) & 0.135 & 0.975 & 0.943 & 1.008 \\
\hline Gender (Female) & 0.758 & 1.111 & 0.568 & 2.173 \\
\hline Occupation with digital screen use & 0.197 & 0.622 & 0.303 & 1.279 \\
\hline work during last month & $0.045 *$ & & & \\
\hline Reduced duty vs no work & 0.882 & 0.940 & 0.418 & 2.116 \\
\hline Work from home vs no work & $0.027 *$ & 2.566 & 1.112 & 5.920 \\
\hline No change vs no work & 0.215 & 1.886 & 0.692 & 5.139 \\
\hline Anti-inflammatory & 0.324 & 1.495 & 0.672 & 3.327 \\
\hline Antihistamines & 0.193 & 1.624 & 0.783 & 3.366 \\
\hline Antidepressants & 0.901 & 1.096 & 0.259 & 4.633 \\
\hline Diabetes mellitus & 0.183 & 0.517 & 0.196 & 1.365 \\
\hline Previous dry eye & $<0.001 *$ & 3.926 & 2.037 & 7.568 \\
\hline Error of refraction & 0.326 & 1.383 & 0.725 & 2.638 \\
\hline Astigmatism & 0.938 & 1.047 & 0.327 & 3.355 \\
\hline Far sight & 0.120 & 2.401 & 0.797 & 7.233 \\
\hline Glass user & 0.127 & 0.632 & 0.350 & 1.140 \\
\hline Altered duration of screen use during day & $<0.001 *$ & 1.992 & 1.422 & 2.791 \\
\hline Altered duration of screen use during night & 0.572 & 1.097 & 0.795 & 1.515 \\
\hline Anxiety & $0.019 *$ & 2.167 & 1.138 & 4.128 \\
\hline Depression & 0.071 & 0.528 & 0.264 & 1.056 \\
\hline Stress scale-4 & $<0.001 *$ & 1.792 & 1.559 & 2.061 \\
\hline
\end{tabular}

CI: confidence interval; OR: odds ratio; *significant at $\mathrm{p} \leq 0.05$. 
By Multiple regression analysis, after adjustment for the confounders, increased duration of VDT use during day and increased PSS-4 by one point were significantly associated with increased severity of DED $(p<0.001)$. Other factors include; female gender $(\mathrm{p}=0.045)$, working during last month $(\mathrm{p}=0.036)$ and receiving dry eye treatment $(\mathrm{p}=0.005)$.

\section{DISCUSSION}

During the current COVID-19 pandemic, a worldwide lockdown had been imposed as a trial to curb this health problem. However, several possible threats on the mental and physical health have been observed including ocular surface disorders ${ }^{20}$.

In order to investigate the possible risk factors associated with the lockdown on the DED symptoms during COVID-19 pandemic, we administered an electronic based survey among participants from the middle east region which was almost under complete curfew for nearly 3 months before the study.

We employed OSDI questionnaire in diagnosing DED among participants. Although it is a self-assessed test, OSDI had demonstrated good sensitivity and specificity in distinguishing between normal subjects and patients with dry eye disease in large scale study ${ }^{14}$. In our survey, almost $30 \%$ of the participants were diagnosed as DED with nearly half of them having history of DED before the lockdown. Thus, the lockdown might be responsible for the developing of the symptoms in only small group of the participants but may aggravate the symptoms in already present disease.

Though OSDI questionnaire displays a unique capacity to assess the frequency of dry eye symptoms, it is not a perfect choice for assessing the severity of the symptoms $^{21}$. So, we utilized a modified dry eye questionnaire (DEQ) to assess the severity of the DED symptoms ${ }^{15-16}$ that was proved to be effective in discriminating self-assessed severity of the DED ${ }^{22}$.

On analyzing DEQ results, $22 \%$ of the already diagnosed DED with OSDI seemed to lack the characteristic DED symptoms. Thus, there might be some misconceptions in the diagnosis of DED when relying only on OSDI results. OSDI questionnaire integrated visual function in the diagnosis as it includes questions related to difficulty with reading, driving at night, working with a computer, and watching TV, which could result in higher scores for reasons related to accommodation rather than pure DED.

Scrutinizing our results regarding the risk factors, it was noticed that the number of participants with astigmatism was significantly higher in the DED group also the number of patients without glasses was higher in the DED. Accommodation is a well-known cause of ocular fatigue. That is why many DED patients show great improvement of signs and symptoms of DED after full correction for their errors of refraction especially hypermetropia ${ }^{23}$.

Glasses may offer some protection acting as a shield hindering transitory vaporization of the lacrimal film ${ }^{23}$. Accordingly, uncorrected errors of refraction might have aggravated the symptoms of eye strain within DED group of patients. Some of our participants might be unable to get their glasses during the lockdown period.

A dual positive relationship between DED and accommodation was further proven by Kaido et al. ${ }^{24}$. Tear film instability in DED was associated with accommodative micro-fluctuation. They assumed that, the up-regulated inflammatory cytokine in the dry eyes can pre-sensitize the nerve fiber in the cornea and orbit. Consequently, the normally innocuous effort of accommodation would produce intolerable retro-orbital 
eye pain. The authors reported improvement of DE symptoms as well as improvement of functional visual acuity after treating the $\mathrm{DED}^{24}$.

A significant association was found between the severity of DED and female gender among our participants. These findings are in accordance with previous studies, where female gender was reported to be associated with higher risk of DED and more severe manifestations ${ }^{8,25,26}$. The exact mechanism is still not specified; however, sex hormones appear to be responsible by altering ocular surface environment ${ }^{26}$.

The use of certain medications was also reported to be related to DED. In the current study, antihistamines showed significant association with the risk of DED. Antihistamines are $\mathrm{H} 1$ receptor antagonists and can reach the lacrimal gland through the blood circulation; therefore, they can affect its muscarinic activity with consequently reduction in the secretion of the lacrimal gland and goblet cells ${ }^{27}$.

It seems that the longer indoor-time during lockdown may have driven individuals to spend longer periods on VDTs. Superadded to this, the resort to distant e-learning and working from home. After adjustment for the confounders, our multivariate Logistic regression revealed that prolonged duration of VDT use during day was significantly associated with increased likelihood and severity of DED. Uchino et al. ${ }^{28}$ carried out similar analysis and found that VDT use for 8 hours or more was associated with increased likelihood of DED.

Longer durations of VDT use for more than 6 hours per day are associated with decreased blinking rates from 20 to 25 times per minute to 5 to 10 times per minute with higher evaporation of tear, leading to instability of tear film and hyperosmolarity. Moreover. Increased sitting time associated with VDT use has been found to increase the risk of DED by $4 \%$ for every one hour per day $^{29}$. Decreased physical activity may also lead to a decrease in tear secretion and can, therefore, increase the risk of developing $\mathrm{DED}^{30}$.

Mental health problems have been identified as potential risk factors of $\mathrm{DED}^{31-32}$. The COVID-19 pandemic has been shown to increase the incidence of mental health problems, among the ${ }^{33-34}$. These findings were confirmed in our study, as the univariate analysis showed that anxiety, depression and higher stress score were risk factors for DES. However, the relationship between DES and the depression did not hold true in the multivariate analysis. On the other hand, Yilmaz et al. ${ }^{35}$ found that depression, anxiety, and stress were associated with increased likelihood of DED. In our questionnaire we had to add an Arabic translation for the items of the survey, the validity of which was tested before ${ }^{36}$.

A proposed explanation for this finding might be the use of anxiolytic and antidepressants, however, this was not proved in our survey. Other possible mechanisms might be the enhanced perception of pain generally, including DED-related eye pain and discomfort ${ }^{37}$, the production of inflammatory cytokines with increasing the risk of inflammatory disorders such as $\mathrm{DED}^{38-39}$.

The present study possesses some points of strength. The main strength of the current research work is being one of the first studies to evaluate psychological stress and increased VDT use as potential factors that can explain the DED-related manifestations reported previously in COVID-19 patients. In addition, our study adjusted for several confounding factors that may have caused or aggravated DED. 
Classification of the participants into DED and nonDED was based only on their response to the OSDI questionnaire with no direct physical examination owing to the current quarantine. This represents an inevitable limitation in most of the questionnaire based-study. Nevertheless, prior work on validation of this questionnaire-based assessment of DES showed a good sensitivity and specificity in the discrimination of DED from normal subjects. Moreover, the questionnaire was not able to investigate every risk factor due to their multiplicity. As most of the responders were in the middle age, age-dependent prevalence was not discussed. Finally, some factors, such as refraction, health status and stress might not be so accurate as they were self-reported.

In conclusion, the COVID-19 lockdown may have led to increased psychological stress and prolonged use of VDTs, which were significantly associated with increased risk and the severity of DED.

\section{Corresponding author}

Correspondence to Sherein M. Hagras

Email: shereinhagras@gmail.com

\section{Affiliations}

Sherein M. Hagras

Mansoura Ophthalmic Center, Mansoura University, Mansoura, Egypt.

\section{Ethics declarations}

\section{Conflict of interest}

Mona A. Nassief, Sherein M. Hagras, Reham A. Amer, Ameera G. Abdelhameed, all authors have no conflicts of interest that are directly relevant to the content of this review.
Funding: No sources of funding were used to conduct this review.

Reviewer disclosures: No relevant financial or other relationships to disclose.

Declaration of interest: No financial affiliations or financial involvement with any organization or entity with a financial competing with the subject matter or materials discussed in the review.

\section{Financial disclosure}

None of authors have any proprietary interests or conflicts of interest related to this submission.

None of the authors received any financial support during this work.

This submission has not been published anywhere previously and that it is not simultaneously being considered for any other publication.

\section{REFERENCES}

1. Eurosurveillance Editorial T. Note from the editors: World Health Organization declares novel coronavirus (2019-nCoV) sixth public health emergency of international concern. Euro surveillance: bulletin Europeen sur les maladies transmissibles $=$ European communicable disease bulletin. 2020;25 (5).

2. Napoli PE, Nioi M. Global Spread of Coronavirus Disease 2019 and Malaria: An Epidemiological Paradox in the Early Stage of A Pandemic. Journal of clinical medicine. 2020;9 (4).

3. Liu J, Liao X, Qian S, et al. Community Transmission of Severe Acute Respiratory Syndrome Coronavirus 2, Shenzhen, China, 2020. Emerging infectious diseases. 2020;26 (6):13201323. 
4. Chen L, Deng C, Chen X, Zhang X, Chen B, Yu H, et al. Ocular manifestations and clinical characteristics of 534 cases of COVID-19 in China: A cross-sectional study. MedRxiv. 2020

5. The definition and classification of dry eye disease: report of the Definition and Classification Subcommittee of the International Dry Eye Work Shop (2007). The ocular surface. 2007; 5 (2):75-92.

6. Stern ME, Gao J, Siemasko KF, Beuerman RW, Pflugfelder SC. The role of the lacrimal functional unit in the pathophysiology of dry eye. Experimental eye research. 2004;78 (3):409-416.

7. Miljanović B, Dana R, Sullivan DA, Schaumberg DA. Impact of dry eye syndrome on vision-related quality of life. Am J Ophthalmol. 2007;143 (3):409415.

8. Uchino M, Schaumberg DA, Dogru M, et al. Prevalence of dry eye disease among Japanese visual display terminal users. Ophthalmology. 2008;115(11):1982-1988.

9. Cho HA, Cheon JJ, Lee JS, Kim SY, Chang SS. Prevalence of dry eye syndrome after a three-year exposure to a clean room. Ann Occup Environ Med. 2014; $26: 26$.

10. Kaido M, Kawashima M, Yokoi N, et al. Advanced dry eye screening for visual display terminal workers using functional visual acuity measurement: the Moriguchi study. The British journal of ophthalmology. 2015;99 (11):1488-1492.

11. Courtin R, Pereira B, Naughton G, et al. Prevalence of dry eye disease in visual display terminal workers: a systematic review and metaanalysis.BMJ open 2016;6 (1): e009675.

12. van der Vaart R, Weaver MA, Lefebvre C, Davis RM. The association between dry eye disease and depression and anxiety in a large population-based study. Am J Ophthalmol. 2015;159 (3):470-474.
13. Ayaki M, Kawashima M, Negishi K, Tsubota K. High prevalence of sleep and mood disorders in dry eye patients: survey of 1,000 eye clinic visitors. Neuropsychiatr Dis Treat.2015;11:889-94.

14. Schiffman RM, Christianson MD, Jacobsen G, Hirsch JD, Reis BL. Reliability and validity of the Ocular Surface Disease Index. Archives of ophthalmology (Chicago, Ill: 1960). 2000;118 (5):615-621.

15. Begley CG, Caffery B, Chalmers RL, Mitchell GL. Use of the Dry Eye Questionnaire to Measure Symptoms of Ocular Irritation in Patients with Aqueous Tear Deficient Dry Eye. Cornea. 2002;21 (7):664-670.

16. Han SB, Yang H K, Hyon J Y, Wee WR. Association of dry eye disease with psychiatric or neurological disorders in elderly patients. Clin Interv Aging2017;12: 785-792.

17. Cohen S, Kamarck T, Mermelstein R. A global measure of perceived stress. Journal of health and social behavior 1983;24 (4):385-396.

18. Kroenke K, Spitzer RL, Williams JB, Löwe B. An ultra-brief screening scale for anxiety and depression: the PHQ-4. Psychosomatics. 2009;50 (6):613-21.

19. Bursac Z, Gauss CH, Williams DK, Hosmer DW. Purposeful selection of variables in logistic regression. Source code for biology and medicine. 2008; 3:17.

20. Pellegrini M, Bernabei F, Scorcia V, Giannaccare G. May home confinement during the COVID-19 outbreak worsen the global burden of myopia? Graefes Arch Clin Exp Ophthalmol. 2020 https://doi.org/10.1007/s00417-020-04728-2

21. Miller KL, Walt JG, Mink DR, Satram-Hoang S, et al. Minimal clinically important difference for the ocular surface disease index. Archives of 
ophthalmology (Chicago, Ill : 1960). 2010;128 (1):94-101.

22. Chalmers RL, Begley CG, Caffery B. Validation of the 5-Item Dry Eye Questionnaire (DEQ-5): Discrimination across self-assessed severity and aqueous tear deficient dry eyediagnoses. Contact Lens and Anterior Eye. 2010;33 (2):55-60.

23. Mai ELC, Lin CC, Lian I, Liao R, Chen M, Chang C. Population-based study on the epidemiology of dry eye disease and its association with presbyopia and other risk factors. Int Ophthalmol. 2019;39 (12):2731-2739.

24. Kaido M, Kawashima M, Ishida R, Tsubota K. Severe symptoms of short tear break-up time dry eye are associated with accommodative microfluctuations. Clinic Ophthalmol2017; 11:861-869

25. Vehof J, SillevisSmitt-Kamminga N, Nibourg SA, Hammond CJ. Sex differences in clinical characteristics of dry eye disease. The ocular surface. 2018;16 (2):242-248.

26. Schaumberg DA, Uchino M, Christen WG, Semba RD, Buring JE, Li JZ. Patient reported differences in dry eye disease between men and women: impact, management, and patient satisfaction. PLoS One. 2013;8 (9): e76121.

27. Fraunfelder FT, Sciubba JJ, Mathers WD. The role of medications in causing dry eye. Journal of ophthalmology. 2012; 2012:285851-.

28. Uchino M, Yokoi N, Uchino Y, et al. Prevalence of dry eye disease and its risk factors in visual display terminal users: the Osaka study. Am J Ophthalmol. 2013; 156(4):759-766.

29. Nakazawa T, Okubo Y, Suwazono Y, et al. Association between duration of daily VDT use and subjective symptoms. Am J Ind Med. 2002; 42:421426. doi: 10.1002/ajim.10133.
30. Kawashima M, Uchino M, Yokoi N, et al. The Association between Dry Eye Disease and Physical Activity as well as Sedentary Behavior: Results from the Osaka Study. J Ophthalmol. 2014; 2014:943786.

31. Li M, Gong L, Sun X, Chapin WJ. Anxiety and depression in patients with dry eye syndrome. Current eye research. 2011;36 (1):1-7.

32. Ulusoy, M.O., Işık-Ulusoy, S. \&Kıvanç, S.A. Evaluation of dry eye disease in newly diagnosed anxiety and depression patients using anterior segment optical coherence tomography. Eye and Vis 2019:6, 25. https://doi.org/10.1186/s40662-0190149-y

33. Liu S, Yang L, Zhang C, et al. Online mental health services in China during the COVID-19 outbreak. The lancet Psychiatry. 2020;7 (4): e17-e8.

34. Bao Y, Sun Y, Meng S, Shi J, Lu L. 2019-nCoV epidemic: address mental health care to empower society. Lancet (London, England). 2020;395 (10224): e37-e8.

35. Yilmaz U, Gokler ME, Unsal A. Dry eye disease and depression-anxiety-stress: A hospital-based case control study in Turkey. Pakistan journal of medical sciences. 2015;31 (3):626-631.

36. Almadi T, Cathers I, Hamdan Mansour AM, Chow $C M$. An Arabic version of the perceived stress scale: translation and validation study. Int $j$ Nurs Stud. 2012; 49(1):84-89.

37. Geva N, Pruessner J, Defrin R. Acute psychosocial stress reduces pain modulation capabilities in healthy men. Pain. 2014;155 (11):2418-2425.

38. Slavich GM, Irwin MR. From stress to inflammation and major depressive disorder: a social signal transduction theory of depression. Psychological bulletin. 2014;140 (3):774-815. 
39. Shields GS, Kuchenbecker SY, Pressman SD, Sumida KD, Slavich GM. Better cognitive control of emotional information is associated with reduced pro-inflammatory cytokine reactivity to emotional stress. Stress (Amsterdam, Netherlands). 2016;19 (1):63-68. 